Bischoff, J., Maciejewski, M., Schlenther, T., \& Nagel, K.

\title{
Autonomous vehicles and their impact on parking search
}

Journal article | Accepted manuscript (Postprint)

This version is available at https://doi.org/10.14279/depositonce-8347

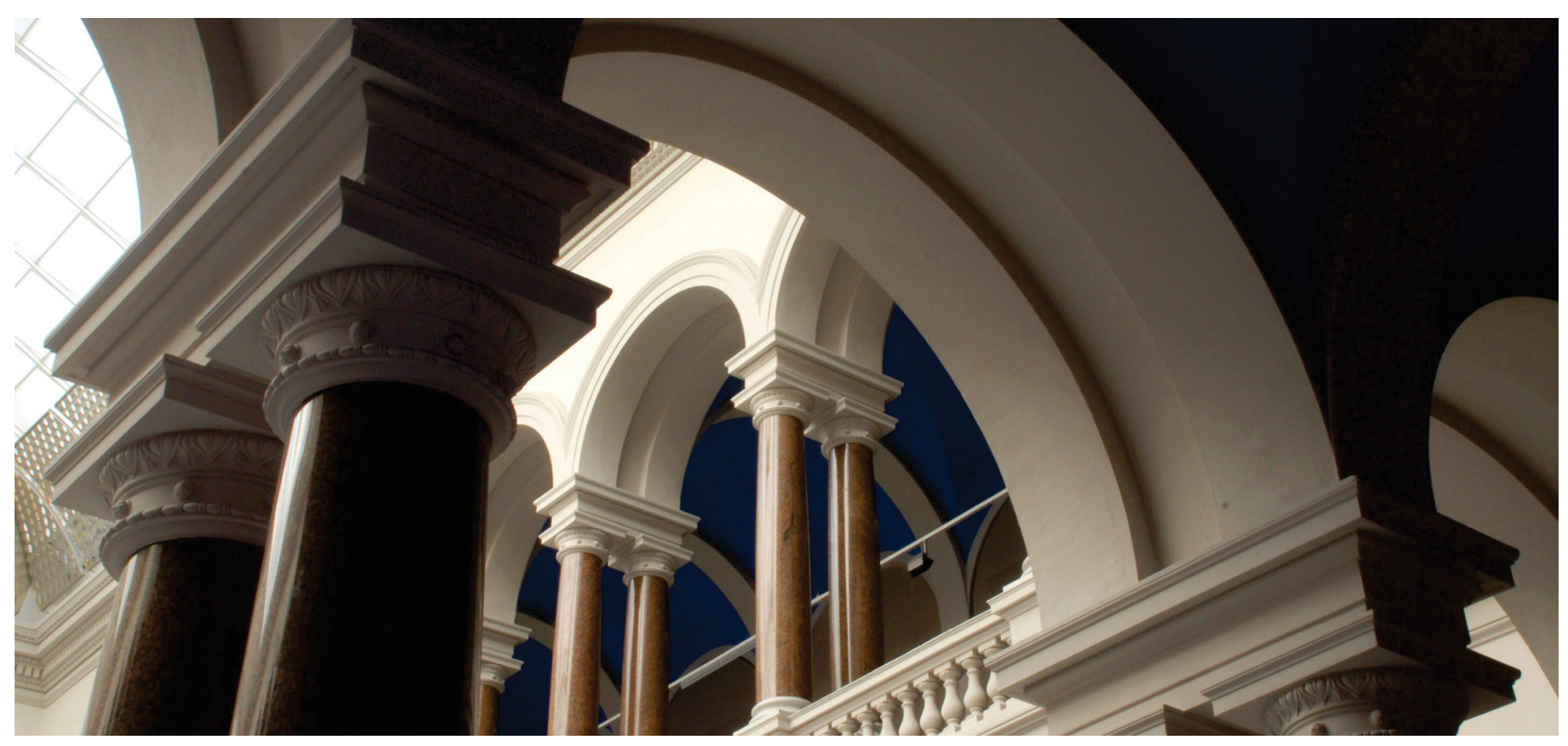

(C) (C) 2018 IEEE. Personal use of this material is permitted. Permission from IEEE must be obtained for all other uses, in any current or future media, including reprinting/republishing this material for advertising or promotional purposes, creating new collective works, for resale or redistribution to servers or lists, or reuse of any copyrighted component of this work in other works.

Bischoff, J., Maciejewski, M., Schlenther, T., \& Nagel, K. (2018). Autonomous Vehicles and Their Impact on Parking Search. IEEE Intelligent Transportation Systems Magazine.

https://doi.org/10.1109/mits.2018.2876566

\section{Terms of Use}

Copyright applies. A non-exclusive, non-transferable and limited right to use is granted. This document is intended solely for 


\title{
Autonomous vehicles and their impact on parking search
}

\author{
Joschka Bischoff, Michal Maciejewski, Tilmann Schlenther, Kai Nagel
}

(Invited Paper)

\begin{abstract}
Parking is a major constraint for car users and therefore an important factor in mode choice decisions. In this paper we introduce a model to simulate parking search behavior for cars within a multi-agent transport simulation, including full simulation of all steps of parking search, such as walking to and from the vehicle. This is combined with the capabilities of privately owned autonomous vehicles (AVs), which may park automatically, often in other locations than conventional cars, once they are not in use. Three different strategies for AVs to park are developed: (1) Conventional parking search, (2) parking at a designated AV lot, and (3) empty cruising, where vehicles do not use any parking space, but keep on driving. We apply the simulation model to a residential neighborhood in central Berlin, where parking pressure is generally high and apply different shares of AV usage to the synthetic population used. This allows a detailed evaluation of effects for both AV and conventional vehicle owners. Results suggest that the usage of designated parking lots may be the most beneficial solution for most users, with both vehicle wait times and parking search durations being the lowest.
\end{abstract}

Index Terms-parking search, autonomous vehicles, transport simulation, MATSim

\section{INTRODUCTION}

Beyond well-known effects of traffic flow and congestion, parking is a major issue of car usage in cities around the globe. This is especially true in European cities, where onstreet, or curbside parking, is the predominating form of vehicle parking.

In recent years, agent-based parking search models have evolved and found usage in several cities. These models aim at simulating parking search behavior for streets or quarters of a city. This approach has proven suitable for modeling additional traffic effects of parking and/or behavioral questions with regard to parking search behavior. At the same time, agent-based transport simulations are a powerful tool to simulate agents' activities and travel patterns, as well as the behavior related to it, on a large scale. There have been several attempts to integrate parking search models into transport simulations, however, to the knowledge of the authors, there is currently only one working simulation available offering both [1].

In the upcoming years, autonomous vehicles may change the way people are using and parking their private vehicles quite drastically, which will lead to a new interplay between

The authors are with the Department for Transport System Planning and Transport Telematics at Technische Universität Berlin, Salzufer 1719, 10587 Berlin, Germany; e-mail: bischoff@vsp.tu-berlin.de. Michal Maciejewski is also with the Poznan University of Technology, Division of Transport Systems.

Manuscript received September 15, 2017; revised December 18, 2017 users of conventional vehicles and AV users. Owners of AVs may pick a totally different parking behavior as the parking search process can be done without any human interaction. This could possibly have an effect on users of conventional vehicles.

In this paper, we introduce an approach to integrate parking search behavior and privately owned autonomous vehicles in an agent-based simulation to analyze possible effects of interplay. The starting point is the parking search simulation that has been introduced previously [1]. To our best knowledge, there is currently no other research that embeds parking search of AVs into microscopic urban transport simulation that would allow to evaluate possible effects of $\mathrm{AV}$ on the transport system as a whole.

\section{STATE OF THE ART}

Parking, parking search and parking choice have been widely researched. On the behavioral side of parking search, papers by Axhausen[2] and Polak and Axhausen[3] provide a comprehensive overview of parking search behavior and ways to model it. The effect of different parking strategies and prices was also investigated by Shoup [4] , who demonstrated why vehicle cruising occurs and explains the influence of parking policy on the behavior of drivers.

Several tools to simulate it are available. One of them is PARKAGENT[5], a multi-agent, spatially explicit model developed as an ArcGIS extension. It allows the simulation of both streetside and garage parking lot locations in city quarters. Agent simulation takes place only during parking search, which is modeled in high detail. The biggest, and to the knowledge of the authors, only simulation scenario published about has been set up for parts of Tel Aviv.

On the contrary, the project SUSTAPARK [6] includes a detailed traffic model of cities so that the influence of parking search into a city's overall traffic state can be simulated. The model is applied for Leuven, Belgium. The model is based on cellular automata. Parts of the software are available under an open source license. A simulation of behavioral change seems only possible in terms of parking, but not in terms of other choice dimensions, such as departure times or mode choice.

Several papers proposed at ETH Zürich have addressed modeling and simulating parking choice in MATSim [7]. Their main focus is on parking choice modeling (e.g., the choice between two differently priced garages) [8], without modeling explicitly related physical activities, such as walking from or to parking lots, or the actual search for a space in a lot. Instead, the length of the walking distance and the 


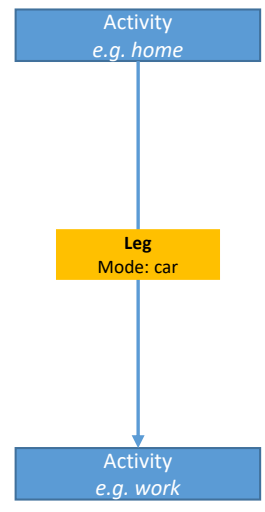

Standard car ride

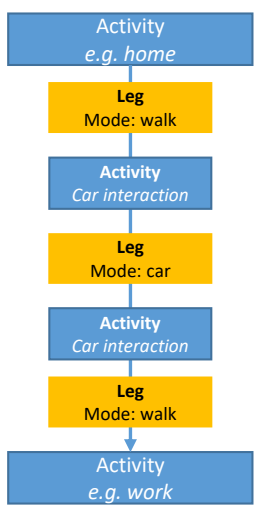

Car ride with parking

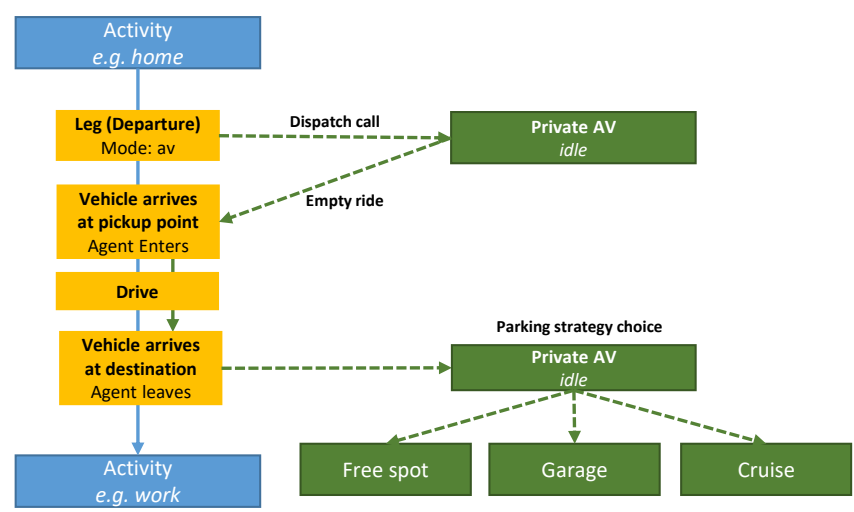

\author{
$\mathrm{AV}$ ride \\ with parking
}

Fig. 1. An agent's car leg using MATSim's standard approach (left side), with walk legs to and from parking in between (center) and using an AV (right)

parking costs reduce an agent's daily score. This approach is very fast from the computational perspective and hence useful for simulating different pricing policies and the like, including mode choice and adaption of agents towards new modes, such as free-floating car sharing [9]. However, by omitting explicit parking search, neither the time lost on parking search is considered nor a possible increase in congestion that affects other agents is assessed. Parking search integration was also proposed [10], but apparently never published.

AVs may have a disruptive effect on both private and public transport, with several possible scenarios evolving from their introduction. On one hand, they offer an enormous amount of opportunities as shared autonomous vehicles (SAVs). These could offer taxi-like services in urban areas and gradually help to reduce the number of vehicles required to serve the demand. Recent simulation studies suggest a replacement rate of up to 1:10, i.e., one SAV could replace ten conventional cars [11]-[13]. Consequuently, parking demand could be reduced significantly, both for off- and on street parking [13], [14]. SAV user costs may be on a similar level as car usage costs [15].

However, studies also suggest that SAV operations may not be economically efficient for operators in areas of low population density [16] and people will rather continue to use their private vehicles instead, which may have full, or at least some, autonomous functionalities, including automated valet parking. Since the total number of vehicles remains the overall same, the effect of private AVs on parking is likely to be less beneficial than the use of shared vehicles.

Also, there will be a phase where autonomous and conventional vehicles will both be common in city traffic and AVs. As to the question, how AVs, indifferent if shared or private, may park once they are idle, most ideas are speculative, including ideas of re-balancing fleet vehicles [17]. Especially in areas with' high parking pressure and / or cost, vehicle owners or fleet providers may chose to park vehicles elsewhere or even let them cruise [18].

AVs, irrespective if shared or privately owned, may also lead to a break through in car-to-car communication. This may ultimately reduce parking cruise to a bare minimum, as vehicles close to each other may share information about free spaces in surrounding areas [19].

\section{Methodology}

In line with the parking choice approach described [10], we also decided to use MATSim as a transport simulation to integrate parking search behavior. The source code of MATSim and its official extensions, including the parking module used in this research, is open and available at https://github.com/matsim-org/matsim. As an agentbased, flexible and pluggable open-source software, its coevolutionary algorithms and customizable scoring functions provide a very versatile base to extend an existing model with parking search behavior [20]. Furthermore, it might be possible to integrate some of the existing parking choice scoring functionality described above with the approach, if required.

The base concept behind the MATSim simulation is the evolution of agents' scores over multiple iterations, originating from a synthetic population created, for instance, from census data. The score of an agent is summed up based on a daily plan of performed activities (usually positive) and traveling (usually negative) [21]. After each iteration, a certain share of agents modify their plans ("dayto-day replanning"). Typical modifications are changes of departure times, travel modes and routes. If the modified plan scores well, it is kept, otherwise discarded again. This process is repeated over several iterations until a stochastic user equilibrium is reached.

In order to model parking search, as well as other processes that cannot be planned ahead for the whole day, MATSim has been extended with several implementations that allow agents to change their behavior within 
an iteration. This feature is often referred to as withinday replanning [22], [23] and has extended application of MATSim to a wide range of different use cases, from evaluating evacuation scenarios [24] through modeling congestion effects of city-wide SAV fleets [25] to benchmarking dynamic vehicle routing algorithms [26].

\section{A. Simulation of parking search behavior}

1) Simulation extension and modification: For an integration of parking search algorithms, a combination of day-to-day and within-day replanning (the latter provided by the DVRP extension [23]) needs to be used. Before each iteration agents may include car trips into their daily plans. These trips, or legs, need to be adjusted during simulation runtime due to non-determinism of parking search. Depending on the location of an agent's vehicle, its route may differ substantially between iterations and thus needs be calculated ad-hoc.

2) Data and computational requirements: Apart from the typical input data required for the MATSim simulation, the number of parking spots on each link in the study area is necessary. For links without this information, a direct on-street parking spot is assumed. Due to the necessity to route each agent ad-hoc, the computational requirements are higher than in standard MATSim simulation runs.

3) Agent logic: During a typical MATSim iteration, an agent starts traveling by car right after performing an activity. The route it travels along is either set at the beginning of the iteration or comes from previous iterations. Upon reaching its destination, the vehicle is removed from traffic and the agent's next activity starts. Thus, an agent may be either in traveling ( $L E G$ ) or activity performing state (ACTIVITY). See Fig. 1 (left) for an overview of this scheme.

In order to simulate parking search, the agent state space needs to be adjusted. Namely, each car leg needs to be split up into several stages: (1) determining the vehicle location and walking there, (2) unparking the vehicle, (3) route calculation and traveling to destination, including searching for parking, (4) parking the vehicle, (5) walking to destination. This means, a single car leg is split into three legs and two activities (cf. to Fig. 1, center). A similar approach is also used for the simulation of schedule-based public transport in MATSim [27].

4) Parking search behavior: A person's parking search behavior may depend on several factors, such as the location, the pricing of parking, personal experiences, the willingness to park illegally, and many more [28]. Therefore it is advisable to allow the search behavior to be agentspecific. To achieve this, the search behavior is kept behind an Interface with every agent having possibly a custom implementation. MATSim's finest granularity in terms of traffic flow is link-based, allowing parking search to be explicit on a link-to-link base.

In this paper, a simple random search logic is used, as depicted in Fig. 2. Initially, an agent drives to their destination along a path that has been pre-calculated upon departure (a). Upon reaching the destination, it traverses along a randomly selected sequence of neighboring links to search for parking (b). Once a link has a free parking spot, the vehicle gets parked (c) and the agent walks to its destination (d). This behavior may be appropriate in areas where there is a certain chance to find parking next to the activity location making it worthwhile to look for a spot here first.

\section{B. Simulation of autonomous vehicles}

MATSim comes with a set of extensions to simulate dynamic modes, including shared autonomous vehicles, by allowing dynamic dispatch of vehicles during the simulation runtime, which, just like parking search, is another form of within-day replanning. A detailed overview of these extensions, including a description how to apply and adapt the code, is available in [26]. Developed use cases include simulation of taxi services [29], pooled DRT services [30] and SAVs [11], [17], [31]. The basic principle behind all these simulations is that upon departure of an agent, a vehicle is assigned for picking up and transporting the agent to its destination. The assignment of vehicles can have certain constraints, depending on the use case. Empty vehicles may be re-allocated or positioned at ranks, if required.

For the simulation of privately owned AVs, a dedicated routing algorithm has been implemented. It assigns each agent always its own private AV. Once an agent finishes its activity and wants to travel by car, its private AV is dispatched from the current location to pick the agent up. Depending on the AV location, the agent has to wait for some minutes for the car to arrive. After dropping off the agent at the destination, the $\mathrm{AV}$ is idle and will proceed according to one of the following options:

- Free spot - Remain where it is, should there be parking available. In this case, the AV will not move from the link where the customer was dropped off. Otherwise find a nearby parking spot in the surroundings. In this case, the vehicle will use the same parking search algorithm (described in the previous section) as for conventional vehicles.

- Garage - Proceed to the nearest not- fully occupied parking lot or garage. Using this strategy, the AV will continue to the closest designated AV garage.

- Cruise - In this case, the AV will cruise in circles around the last drop off point until it is required again within a defined radius around the point.

While the first option results in the parking search behavior typical to human drivers, garages are only used for AVs in this paper. If these are designed to be used only by AVs, they may be built in a less space-consuming way. The possibility to let vehicles cruise instead of searching for parking is an often-feared scenario, especially for areas where parking charges are high.

Once an agent has finished its activity and requires the vehicle again, it is dispatched from its current idle location to pick the agent up. Depending on the vehicle location, the agent has to wait for some minutes for the car to arrive. All the software developed in this paper is available freely under open-source licenses. 


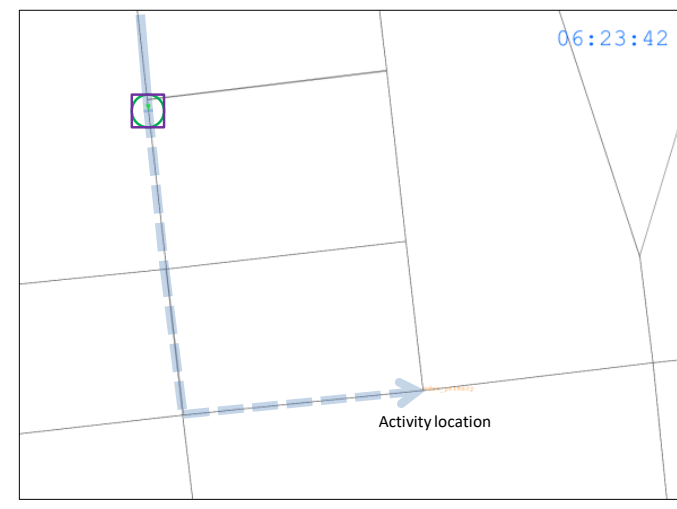

(a)

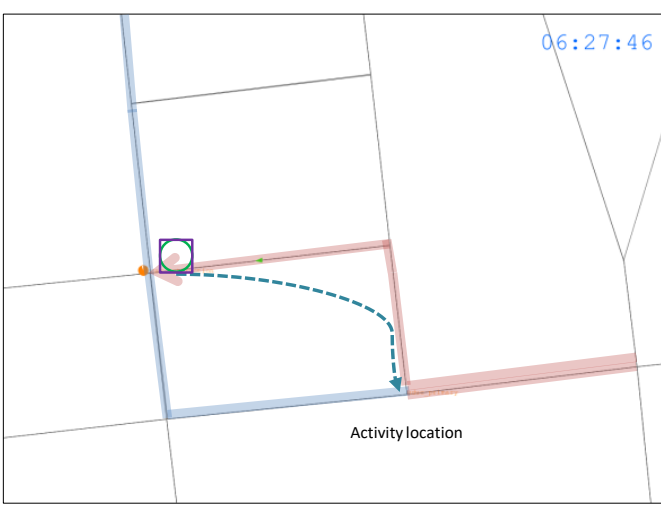

(c)

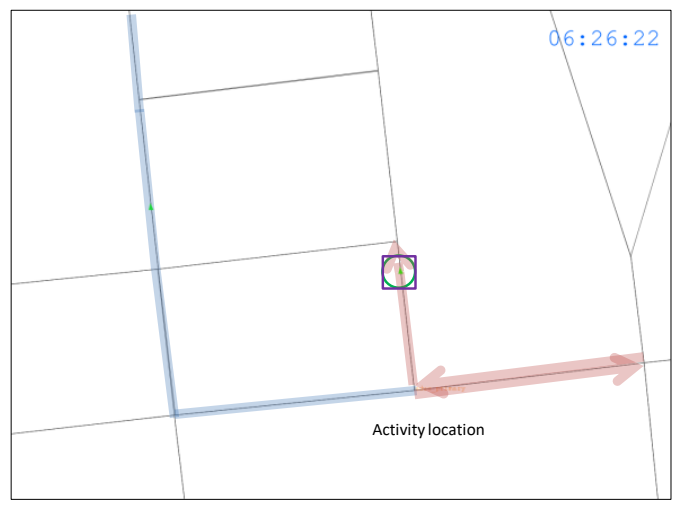

(b)

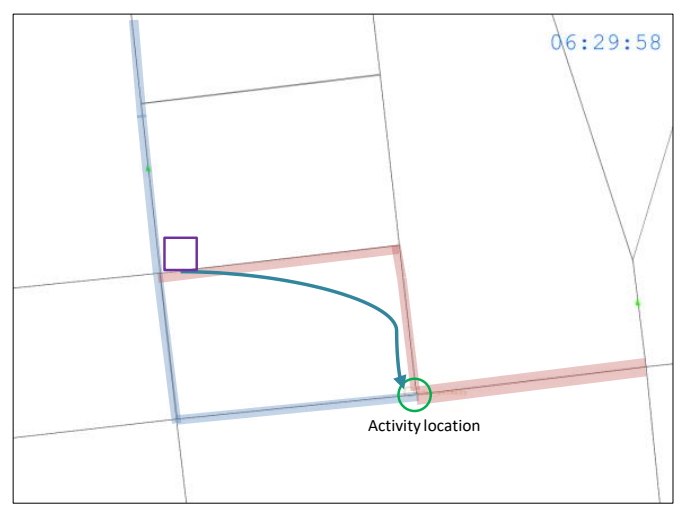

(d)

Fig. 2. Parking search process

\section{SCENARIO ADAPTATION AND PARKING INTEGRATION}

The parking search framework developed is applied to an existing MATSim Berlin scenario [32]. Data about parking spaces and their occupancy during nighttime is available for a distinct area in the Charlottenburg district, around the Klausenerplatz. The area is surrounded by a motorway to the east and to major arterial roads in the north and south, so car users tend to park their vehicle within these barriers. Consequently, parking pressure in the area is known to be high. Fig. 3 provides an overview of the study area. Roughly 4000 curbside parking spaces exist in the area and are used in the model. These were counted during a student project in 2016, were also the overall parking room occupancy in the area was analyzed.

For computational reasons, the synthetic population of the original scenario with 6 million agents was reduced to those agents who perform at least one activity in the area or its immediate surroundings, leaving roughly 37000 agents. Travel times on links outside the area were assumed to be the same as in the base case using dynamically changing network attributes. In order to evaluate the influence of AVs on the parking situation, the simulation was run with several degrees of AV usage: 0,10 and $20 \%$ of the population was equipped with an AV. The case where AVs are not present is referred to as the base case.

In all runs, 50 iterations were simulated. Agents had

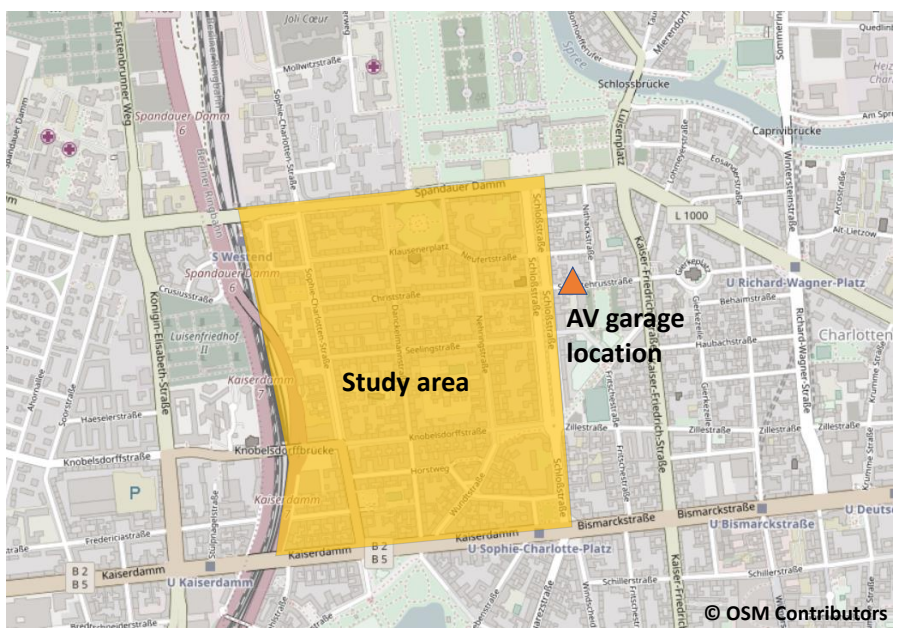

Fig. 3. Study area and the designated AV garage location

the choice of modifying their departure times within a 15minutes interval. For parking locations, iterations were seen as days. This means an agent picks up a car in the morning where it was parked last in the preceding iteration. For AVs, all of the parking strategies defined in the previous section (III-B) where used. Furthermore, a simulation was run where AVs randomly (uniform distribution) pick one of the idle strategies. There is a single garage of unlimited 
capacity to park AVs at the eastern edge of the study area. For the cruising strategy, AVs may circle with a radius of up to 2000 meters around the position where they dropped off their owner at the allowed cruising speed.

\section{Simulation RESUlts}

The introduction of AVs with self-parking and cruising capabilities may have several impacts. Firstly, there are individual impacts for users of both conventional vehicles and AVs: depending on the parking strategy AVs choose, they may or may not compete for parking space with conventional cars and may have an impact on the parking search duration of drivers of ordinary vehicles. Furthermore, the waiting time for owners of AVs may differ depending on the location of the idle vehicle. A nearby parking spot may be more favorable here. Finally, there are effects on the transport network as a whole: AVs that cruise or go to parking in a special garage produce additional idle mileage, which may be partly compensated by conventional vehicles that now have a shorter parking search duration. A comprehensive overview of the simulation results is provided in Table I.

\section{A. Parking search duration}

In the base case, the average duration to find a parking space is 8:50 minutes. This time varies during the day and is particularly long during late morning hours, when people commute into the area for work or other activities. During this peak hour, the average search time is almost 12 minutes (see Fig. 4).

When AVs are introduced, parking search time for conventional cars generally reduces. As anticipated, search times are usually lower in the $20 \% \mathrm{AV}$ scenarios than in the $10 \%$ cases.

In the cases where AVs share free parking slots with conventional vehicles (marked orange in Fig. 4), search times are roughly as long as in the base case.

Search times notably drop by more than 30 seconds in the $10 \%$ case and over 90 seconds in the $20 \%$ case when AVs are not parking but are sent to cruise around (marked yellow in Fig. 4). Parking pressure is reduced significantly.

The usage of a dedicated garage facility for AVs can further improve the search time (marked blue in Fig. 4), which is then calculated to be 8:06 minutes for a $10 \%$ AV share or 7:05 minutes for the $20 \%$ AV share. While both demand and supply of parking spaces are obviously similar in the garage and in the cruise case, the AVs cause additional congestion in the cruise scenario, which increases the overall search time for car users.

The random selection of a strategy (marked in gray) scores somewhere in between the cruise and the parking slot strategy.

\section{B. Wait vs. walk times}

For AV users, the time it takes to recover a vehicle from its idle location can be used to some extent productively, as opposed to a walk to the car, which only may be perceived

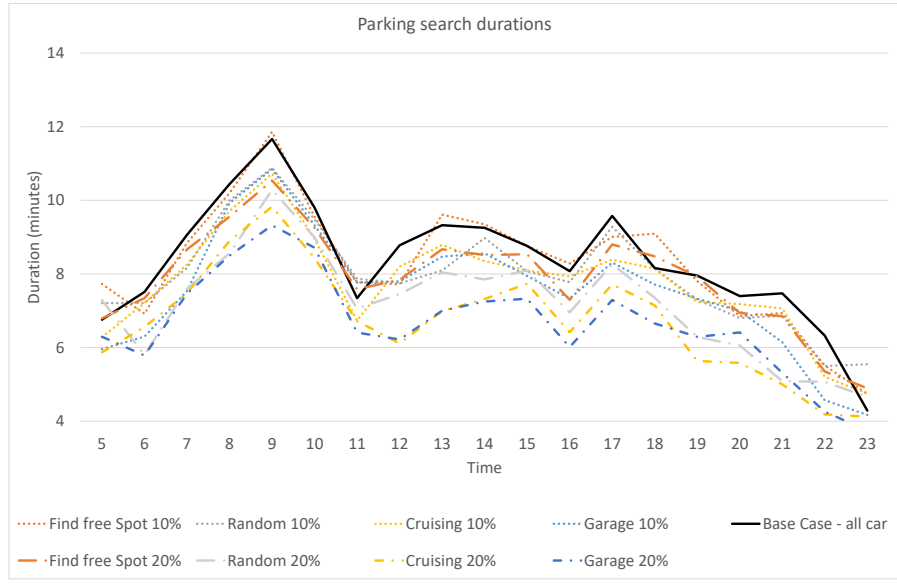

Fig. 4. Parking search durations in the base case and with different levels of AV usage and AV parking strategies

as a positive thing, but is hard to measure in an economical sense. Despite this, long waiting times are undesirable, especially for spontaneous departures and the waiting time should therefore be short.

Both in the $10 \%$ and $20 \%$ scenario, wait times are roughly the same within each strategy. For the random, garage and nearest parking spot strategies these are generally similar in the range of 3:00 to 3:30 minutes. The waiting time is higher for the cruise strategy, with around five minutes. Obviously, this value could be smaller if the cruising radius was set to a lower value. However, all in all, wait times are short in all scenarios and will most likely not be of real significance for AV owners. From the car drivers' perspective, walking between the vehicle and activity location is often as important as parking search, especially because the walk is made both ways. As long as AVs compete with conventional cars for curbside parking, the walk times remain at the same levels as in the base case. However, once AVs are ordered either to park at the designated garage or cruise, the availability of parking spaces increases and thus the time spent by car drivers on both finding a free slot and walking to/from the vehicle decreases. It should be pointed out that savings made on the walk time ought to be counted twice (leaving the car and getting back). In the $20 \%$ Garage scenario, for instance, the total walk time per each activity is reduced by more than a minute compared to the base scenario. However, despite some improvements resulting from AVs being sent to the designated garage, non-AV drivers still need to spend approximately 20 minutes on searching and walking (per activity), which is much more than around 3.5 minutes of waiting for the $\mathrm{AV}$ to come.

\section{Vehicle kilometers}

Due to their capability of driving without a passenger onboard, AVs will increase the driven distances. This implies that the vehicle kilometers traveled will increase in all AV scenarios, mainly due to pick up trips, where agents otherwise would have walked. Compared to the base case, the additional empty mileage is around $2 \%$ in the free slot 
TABLE I

SIMULATION RESULTS FOR DIFFERENT SHARES OF AVS AND PARKING SEARCH STRATEGIES

\begin{tabular}{|c|c|c|c|c|c|c|c|}
\hline AV Share & AV Parking Strategy & $\begin{array}{c}\text { Average parking } \\
\text { search duration } \\
\text { (AV and car) } \\
{[\mathrm{mm}: \mathrm{ss}]}\end{array}$ & $\begin{array}{r}\text { Average wait } \\
\text { time for AV } \\
\\
{[\mathrm{mm}: \mathrm{ss}]} \\
\end{array}$ & $\begin{array}{c}\text { Average walk } \\
\text { time to/from car } \\
{[\mathrm{mm}: \mathrm{ss}]}\end{array}$ & $\begin{array}{r}\text { VKT car } \\
{[\mathrm{km}]} \\
\end{array}$ & $\begin{array}{r}\text { VKT AV } \\
{[\mathrm{km}]}\end{array}$ & $\begin{array}{r}\text { total VKT } \\
{[\mathrm{km}]}\end{array}$ \\
\hline $0 \%$ & base case & 08:50 & $\mathrm{n} / \mathrm{a}$ & $7: 10$ & 521686 & 0 & 521686 \\
\hline $\begin{array}{l}10 \% \\
10 \% \\
10 \% \\
10 \%\end{array}$ & $\begin{array}{l}\text { Free Spot } \\
\text { Garage } \\
\text { Cruise } \\
\text { Random }\end{array}$ & $\begin{array}{l}08: 45 \\
08: 06 \\
08: 16 \\
08: 25\end{array}$ & $\begin{array}{l}03: 22 \\
03: 35 \\
05: 09 \\
03: 15\end{array}$ & $\begin{array}{l}7: 10 \\
6: 56 \\
6: 58 \\
7: 03\end{array}$ & $\begin{array}{l}466556 \\
465424 \\
465667 \\
465865\end{array}$ & $\begin{array}{r}67234 \\
67987 \\
428 \quad 827 \\
166 \quad 102\end{array}$ & $\begin{array}{l}533790 \\
533411 \\
894494 \\
631967\end{array}$ \\
\hline $\begin{array}{l}20 \% \\
20 \% \\
20 \% \\
20 \%\end{array}$ & $\begin{array}{l}\text { Free Slot } \\
\text { Garage } \\
\text { Cruise } \\
\text { Random }\end{array}$ & $\begin{array}{l}08: 23 \\
07: 05 \\
07: 15 \\
07: 39\end{array}$ & $\begin{array}{l}03: 28 \\
03: 39 \\
04: 54 \\
03: 23\end{array}$ & $\begin{array}{l}7: 02 \\
6: 37 \\
6: 42 \\
6: 49\end{array}$ & $\begin{array}{ll}412 & 370 \\
410 & 375 \\
410 & 560 \\
411 & 220\end{array}$ & $\begin{array}{l}133494 \\
134673 \\
684854 \\
295078\end{array}$ & $\begin{array}{r}545864 \\
545048 \\
1095414 \\
706298\end{array}$ \\
\hline
\end{tabular}

and garage strategies in the $10 \% \mathrm{AV}$ scenarios and around $4 \%$ in the $20 \%$ scenarios. This additional empty mileage can most likely be coped easily due to the expected road capacity increase, as literature suggests [25]. For most links in the study area, the increase in daily volumes per link is less than 200 for a $20 \% \mathrm{AV}$ share, as Fig. 5 shows for these strategies. In the cruise scenario, the mileage driven by all is increased by almost $80 \%$ in the $10 \%$ scenario and more than doubled in the $20 \%$ case. This shows clearly the possible impact should vehicle owners be allowed to use such strategies. This increase in mileage spreads along all links in the network. For the study area, arterial roads would have to cope with more than 4000 additional vehicles per day, and more than 1000 additional vehicles in residential streets, which is an increase of two to three times compared to the base case.

\section{CONCLUSION}

With the integration of parking search into a multi-agent transport simulation we were able to show the influence

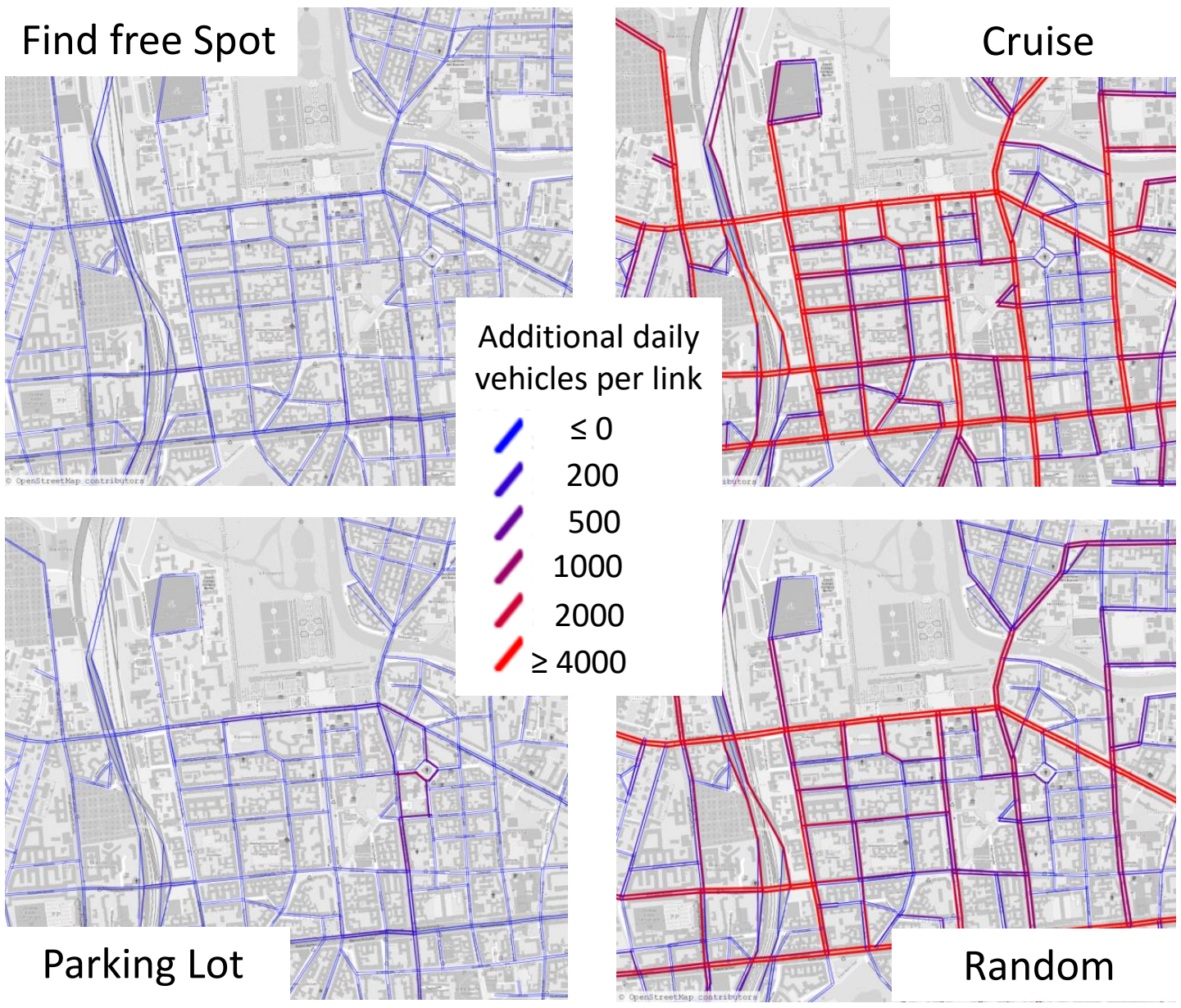

Fig. 5. Changes in daily traffic volumes in the $20 \%$ AV case compared to the base case. 
autonomous vehicles may have on city life. Only some possible, of all the enormous capabilites AVs have, are discussed here. These show both the potential of AVs to solve parking problems in cities, but also highlight new problems arising from them. Of the strategies tested in this paper, sending AVs to a designated parking infrastructure seems to be most promising: The negative effects of parking lots, namely long access ways, can be overcome when using AVs, and parking search for conventional vehicles can be decreased. With a higher share of AVs, the removal of curbside parking locations may also be discussed. These positive side effects can easily compensate additional mileage created by empty driving AVs. Should AVs simply start searching for parking spaces like conventional vehicles, the parking search situation will remain as it is now. This would be only beneficial for AV users, who do not have to spend time on parking search.

The option most feared in literature, namely an endless cruising of vehicles, does not seem to be beneficial for AV users themselves, as waiting times to recover the vehicle are higher due to congestion and the actual vehicle's location. Additionally, cruising vehicles create significant direct operating costs, which could only be recovered if parking charges are even higher than these. This, however, seems not very probable, considering that vehicle owners may let their vehicles use cheaper parking lots farther away.

This also leads to additional research questions. These include the choice between AV parking policies if costs for parking and externalities are included into the model and passed on to their owners. Further research should also deal with a bigger area and a city-wide model, which may lead to more interactions between agents. Working on both points will also allow to provide more explicit public parking policy recommendations for AVs.

\section{ACKNOWLEDGMENT}

The authors would like to thank the BMW Group for cofunding parts of this paper.

\section{REFERENCES}

[1] J. Bischoff and K. Nagel, "Integrating explicit parking search into a transport simulation," Procedia Computer Science, vol. 109, pp. 881-886, 2017. [Online]. Available: http://www.sciencedirect.com/ science/article/pii/S1877050917310906

[2] K. Axhausen, "Ortskenntnis und Parkplatzwahlverhalten, report to the Deutsche Forschungsgemeinschaft," Institut für Verkehrswesen, Universität (TH) Karlsruhe, Karlsruhe, 1989.

[3] J. Polak and K. Axhausen, "Parking search behaviour: A review of current research and future prospects," Transport Studies Unit, University of Oxford, Working Paper 540, 1990.

[4] D. C. Shoup, "Cruising for parking," Transport Policy, vol. 13, no. 6, pp. 479-486, 2006, parking. [Online]. Available: http: //www.sciencedirect.com/science/article/pii/S0967070X06000448

[5] I. Benenson, K. Martens, and S. Birfir, "Parkagent: An agent-based model of parking in the city," Computers, Environment and Urban Systems, vol. 32, no. 6, pp. 431-439, 2008, geoComputation: Modeling with spatial agents. [Online]. Available: http://www.sciencedirect. com/science/article/pii/S0198971508000689

[6] K. Spitaels, S. Maerivoet, G. De Ceuster, G. Nijs, V. Clette, P. Lannoy, K. Dieussaert, K. Aerts, and T. Steenberghen, "Optimising price and location of parking in cities under a sustainability constraint (sustapark)," Belgian Science Policy, vol. Final Report, 2009.
[7] A. Horni, K. Nagel, and K. W. Axhausen, Eds., The Multi-Agent Transport Simulation MATSim. Ubiquity, London, 2016. [Online]. Available: http://matsim.org/the-book

[8] R. A. Waraich, "Parking," in The Multi-Agent Transport Simulation MATSim, A. Horni, K. Nagel, and K. W. Axhausen, Eds. Ubiquity, London, 2016, ch. 13. [Online]. Available: http://matsim.org/the-book

[9] M. Balac, F. Ciari, and R. A. Waraich, "Modeling the impact of parking price policy on free-floating carsharing: Case study for Zurich, Switzerland," in World Conference on Transport Research - WCTR 2016 Shanghai, 2016.

[10] R. A. Waraich, "Modelling parking search behaviour with an agentbased approach," International Conference on Travel Behaviour Research (IABTR), 2012.

[11] J. Bischoff and M. Maciejewski, "Simulation of city-wide replacement of private cars with autonomous taxis in Berlin," Procedia Computer Science, vol. 83, pp. 237-244, 2016. [Online]. Available: http: //www.sciencedirect.com/science/article/pii/S1877050916301442

[12] D. J. Fagnant and K. M. Kockelman, "The travel and environmental implications of shared autonomous vehicles, using agent-based model scenarios," Transportation Research Part C: Emerging Technologies, vol. 40, pp. 1-13, 2014. [Online]. Available: http: //www.sciencedirect.com/science/article/pii/S0968090X13002581

[13] L. Martinez, "Urban Mobility System Upgrade - How shared selfdriving cars could change city traffic," International Transport Forum, Tech. Rep., 2015.

[14] W. Zhang, S. Guhathakurta, J. Fang, and G. Zhang, "Exploring the impact of shared autonomous vehicles on urban parking demand: An agent-based simulation approach," Sustainable Cities and Society, vol. 19, no. Supplement C, pp. 34-45, 2015. [Online]. Available: http: //www.sciencedirect.com/science/article/pii/S221067071530010X

[15] P. Boesch, F. Ciari, and K. Axhausen, "Required autonomous vehicle fleet sizes to serve different levels of demand," Transport Research Board, Tech. Rep., 2016.

[16] J. Bischoff and M. Maciejewski, "Autonomous taxicabs in Berlin a spatiotemporal analysis of service performance," Transportation Research Procedia, vol. 19, pp. 176-186, 2016.

[17] K. Winter, O. Cats, B. van Arem, and K. Martens, "Impact of relocation strategies for a fleet of shared automated vehicles on service efficiency, effectiveness and externalities," in 2017 5th IEEE International Conference on Models and Technologies for Intelligent Transportation Systems (MT-ITS), Jun. 2017, pp. 844-849.

[18] T. Litman, "Autonomous Vehicle Implementation Predictions," Victoria Transport Policy Institute, 2017. [Online]. Available: http: //www.vtpi.org/avip.pdf

[19] M. Caliskan, A. Barthels, B. Scheuermann, and M. Mauve, "Predicting parking lot occupancy in vehicular ad hoc networks," in 2007 IEEE 65th Vehicular Technology Conference - VTC2007-Spring, Apr. 2007, pp. 277-281.

[20] A. Horni, K. Nagel, and K. W. Axhausen, "Introducing MATSim," in The Multi-Agent Transport Simulation MATSim, A. Horni, K. Nagel, and K. W. Axhausen, Eds. Ubiquity, London, 2016, ch. 1. [Online]. Available: http://matsim.org/the-book

[21] K. Nagel, B. Kickhöfer, A. Horni, and D. Charypar, "A closer look at scoring," in The Multi-Agent Transport Simulation MATSim, A. Horni, K. Nagel, and K. W. Axhausen, Eds. Ubiquity, London, 2016, ch. 3. [Online]. Available: http://matsim.org/the-book

[22] C. Dobler and K. Nagel, "Within-day replanning," ch. 30.

[23] M. Maciejewski, "Dynamic transport services," in The Multi-Agent Transport Simulation MATSim, A. Horni, K. Nagel, and K. W. Axhausen, Eds. Ubiquity, London, 2016, ch. 23. [Online]. Available: http://matsim.org/the-book

[24] G. Lämmel, D. Grether, and K. Nagel, "The representation and implementation of time-dependent inundation in large-scale microscopic evacuation simulations," Transportation Research Part C: Emerging Technologies, vol. 18, no. 1, pp. 84-98, 2010.

[25] M. Maciejewski and J. Bischoff, "Congestion effects of autonomous taxi fleets," Transport, vol. 0, no. 0, pp. 1-10, 2017. [Online]. Available: http://dx.doi.org/10.3846/16484142.2017.1347827

[26] M. Maciejewski, J. Bischoff, S. Hörl, and K. Nagel, "Towards a testbed for dynamic vehicle routing algorithms," in Highlights of Practical Applications of Cyber-Physical Multi-Agent Systems: International Workshops of PAAMS 2017, Porto, Portugal, June 21-23, 2017, Proceedings, J. Bajo, Z. Vale, K. Hallenborg, A. P. Rocha, P. Mathieu, P. Pawlewski, E. Del Val, P. Novais, F. Lopes, N. D. Duque Méndez, V. Julián, and J. Holmgren, Eds. Springer International Publishing, 2017, pp. 69-79. 
[27] M. Rieser, "Adding Transit to an Agent-Based Transportation Simulation: Concepts and Implementation," Ph.D. dissertation, TU Berlin, Berlin, 2010.

[28] S. Belloche, "On-street parking search time modelling and validation with survey-based data," Transportation Research Procedia, vol. 6, pp. 313-324, 2015.

[29] M. Maciejewski, J. Bischoff, and K. Nagel, "An assignment-based approach to efficient real-time city-scale taxi dispatching," IEEE Intelligent Systems, vol. 31, no. 1, pp. 68-77, Jan. 2016.

[30] J. Bischoff, M. Maciejewski, and K. Nagel, "City-wide Shared Taxis: A Simulation Study in Berlin," submitted to ITSC 2017, Tech. Rep., 2017, available http://www.vsp.tu-berlin.de/publications/vspwp/ as WP 1711.

[31] S. Hörl, "Agent-based simulation of autonomous taxi services with dynamic demand responses," Procedia Computer Science, vol. 109, pp. 899-904, 2017. [Online]. Available: http://www.sciencedirect. com/science/article/pii/S1877050917310943

[32] A. Neumann, "Berlin i: Bvg scenario," in The Multi-Agent Transport Simulation MATSim, A. Horni, K. Nagel, and K. W. Axhausen, Eds. Ubiquity, London, 2016, ch. 53. [Online]. Available: http://matsim.org/the-book

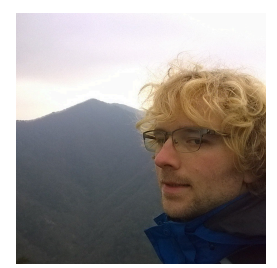

Joschka Bischoff is a research associate and $\mathrm{PhD}$ candidate working at the department for transport systems planning and transport telematics at TU Berlin. His main field of expertise is the simulation of dynamic transport modes, including autonomous vehicles and taxis. Previously, he has studied transportation planning and operations.

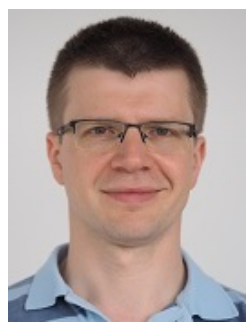

Michal Maciejewski is an assistant professor in Department of Transport Systems at Poznan University of Technology and a senior researcher in the Department of Transport Systems Planning and Transport Telematics at TU Berlin. His research focuses on dynamic vehicle routing, ondemand transport services, e-mobility and autonomous vehicles.

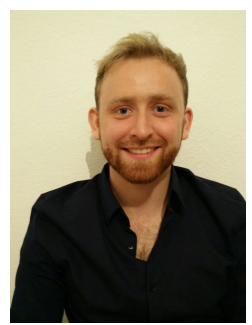

Tilmann Schlenther Tilmann Schlenther is a graduate student at TU Berlin and co-worker at the department for transport systems planning and transport telematics at TU Berlin. He has been working on integrating parking data and the simulation of parking search behavior intensively.

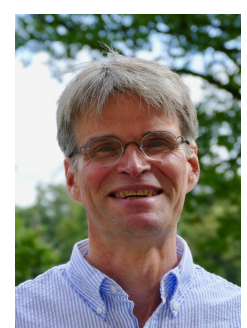

Kai Nagel Kai Nagel is professor for transport systems planning and transport telematics at TU Berlin, specializing in modelling and large-scale simulation of travel behavior and traffic flow. $\mathrm{He}$ has a $\mathrm{PhD}$ in Computer Science from the University of Cologne; from 1995 to 1999 he was at Los Alamos National Laboratory as part of the TRANSIMS team. He is one of the creators of MATSim. 